\section{Thyroid Peroxidase and Thyroglobulin Antibodies and Ophthalmopathy in Patients with Graves' Disease, Hashimoto Thyroiditis and Transient Thyroiditis}

\section{Jack R Wall*, Hooshang Lahooti and Ilhem El Kochairi}

Department of Medicine, University of Sydney, Nepean Clinical School Nepean Hospital, Kingswood, Australia

\begin{abstract}
Background

Inflammation of the orbital connective tissue, extraocular muscles and upper eyelids occurs in about $40 \%$ of patients with Graves hyperthyroidism [Graves Ophthalmopathy (GO)] while mild eye signs including upper eyelid retraction are found in as many as $25 \%$ of patients with Hashimoto thyroiditis and, occasionally, transient thyroiditis. Some workers have proposed a relationship between Thyroid Peroxidase (TPO) and Thyroglobulin (TG) antibodies and GO.

Methods

TPO and TG antibodies were measured using a Standard Enzyme-Linked Immunosorbent Assay (ELISA) in 84 well-characterised patients 39 with Graves' Disease (GD), 33 with Hashimoto thyroiditis and 12 with transient (subacute, silent) thyroiditis, with and without eye signs.

\section{Results}

Twenty-one \% of GD patients with active ophthalmopathy and $30 \%$ of those without eye signs had negative TPO antibody tests and the ranges of titres and mean titres were similar in the two groups, for both antibodies. Although the prevalence of negative TPO antibody tests in patients with long standing (chronic) Graves disease and ophthalmopathy $(67 \%)$ was greater than that in patients with long standing hyperthyroidism but no eye signs $(20 \%)$ this difference was not statistically significant, possibly because the group sizes were
\end{abstract}

*Corresponding author: Jack R Wall, Department of Medicine, University of Sydney, Nepean Clinical School, Nepean Hospital, Kingswood NSW 2751, Australia, Tel: + 61 0247342613; Fax: +61 0247342614; E-mail: jack.wall@sydney.edu.au

Citation: Wall JR, Lahooti H, El Kochairi I (2016) Thyroid Peroxidase and Thy roglobulin Antibodies and Ophthalmopathy in Patients with Graves' disease, Hashimoto Thyroiditis and Transient Thyroiditis. J Hum Endocrinol 1: 002.

Received: January 18, 2016; Accepted: March 28, 2016; Published: April 11, 2016

Copyright: @ 2016 Wall JR, et al., This is an open-access article distributed under the terms of the Creative Commons Attribution License, which permits unrestricted use, distribution, and reproduction in any medium, provided the original author and source are credited. small. In patients with Hashimoto thyroiditis and transient (sub acute, silent) thyroiditis the prevalence's of negative TPO antibody tests, range of titres and mean (+/- SE) titres, were again not significantly different between those with and without eye signs for either disorder. Similar results were found for TG antibodies in all groups of patients, with no significant differences between those with and without ophthalmopathy.

\section{Conclusion}

Overall, we have not shown any significant relationship between negative TPO or TG antibody tests, or low serum titres of either antibody, and eye signs, in patients with GD, Hashimoto thyroiditis or transient thyroiditis. TPO and TG antibodies are thus unlikely to play a major role in the pathogenesis of GO.

Keywords: Graves' disease; Hashimoto thyroiditis; Ophthalmopathy; Thyroid antibodies; Transient thyroiditis

\section{Introduction}

Inflammation of the Orbital Connective Tissue (OCT) and fat, extraocular muscles and the levator palpebrae superioris muscle in the upper eyelids occurs in about $40 \%$ of patients with Graves hyperthyroidism [1-3] while generally mild eye signs or isolated Upper Eyelid Retraction (UER) occurs in about $25 \%$ of patients with Hashimoto thyroiditis [4] and, occasionally, in patients with transient thyroiditis [5]. The best name for this disorder is "Thyroid-Associated Ophthalmopathy (TAO)". In about $10 \%$ of cases, the eye changes occur in the apparent absence of thyroid autoimmunity, so-called "euthyroid Graves disease" [3]. The mechanism for autoimmune-mediated inflammation in the eye muscles and OCT and fat is unclear but a popular hypothesis is that autoimmunity against the TSH-Receptor (TSHR) expressed in the orbital pre adipocytes and fibroblasts [6-8], or eye muscle cell [9], may initiate the inflammatory changes. While the extra ocular muscle reaction, which can occur in the absence of OCT and fat inflammation, may be a separate TAO subtype $[10,11]$, it has not been shown conclusively that the two types differ from Nunery types 1 (mainly involving the orbital fat without restrictive myopathy) and 2 (with diplopia and restrictive myopathy) [12]. Earlier, we showed that chronic UER can be the dominant or only eye sign, except for mild proptosis, in patients with Graves Disease (GD), Hashimoto thyroiditis and transient (sub acute, silent) thyroiditis [13].

Theories to explain the development of ophthalmopathy in patients with Graves' hyperthyroidism must take into account this unique association. Many workers have investigated the possible existence of auto antigens that are expressed in both the thyroid and orbit $[5,13-15]$. Such antigens include the TSHR $[7,8,16]$, the $64-\mathrm{kDa}$ protein, now identified as the Flavoprotein (Fp) sub-unit succinate dehydrogenase [17] or some other, as yet unidentified, thyroid and eye muscle shared cell membrane antigen. Another recently identified target antigen in TAO is type XIII collagen which is expressed in the surface of the orbital fibroblast [18] where it could be seen by the immune system, leading to antibody production, glycosaminoglycans production, fibroblast stimulation and orbital scaring $[19,20]$.

Because of this link with thyroid inflammation some workers have addressed the possibility of a relationship between antibodies targeting the thyroid antigens, Thyroid Peroxidase (TPO) and 
Thyroglobulin (TG) and ophthalmopathy. Indeed, we have recently shown that high serum levels of TPO antibodies were protective against the development of UER but not ophthalmopathy [21]. Earlier, Khoo et al., [22,23] proposed that the combination of negative anti-TPO antibody tests or low titres of TPO antibodies, positive TSHR antibodies and smoking, indicates high risk for ophthalmopathy. However, others $[24,25]$ have failed to confirm these findings and a relationship between thyroid antibodies and the eye disorder is not proven. Here, we have addressed a possible relationship between TPO and TG antibodies, ophthalmopathy and chronic UER in patients with GD, Hashimoto thyroiditis and transient thyroiditis.

\section{Clinical Subjects and Methods}

The patients were seen over a four-year period from 2002-2006 at the thyroid clinic at Nepean Hospital, Kingswood, and the Geelong Hospital, Geelong, Australia. The following groups of patients were studied;

1. Thirty-nine patients with GD, 6 males and 33 females, aged 14-76 (mean age 47 yrs), 34 with recent onset disease and 5 with long standing (chronic) disease, of whom 24 had some eye signs, namely, active ophthalmopathy in 14 , chronic ophthalmopathy in 6 , dominant chronic UER in 16, which was the only eye sign except for mild proptosis in 4 of the patients. Fifteen of the patients, 10 with recent onset disease and 5 with long-standing hyperthyroidism, had no eye signs.

2. Thirty-three patients with Hashimoto thyroiditis, 3 males and 30 females, aged 10-75 (mean age 49 yrs) of whom 4 had active ophthalmopathy and 14 chronic UER, which was the only eye sign in 11 of the patients.

3. Twelve patients with transient thyroiditis namely, 5 with Subacute Thyroiditis (SAT) and 7 with Silent Thyroiditis (ST), one male and 11 female aged 24-68 (mean age 43 yrs) of whom 7 had active ophthalmopathy and 4 had chronic UER but no other features of ophthalmopathy.

The diagnoses of the various disorders were based on standard clinical criteria and confirmed by thyroid function testing, real-time thyroid ultrasonography and immunological tests. The ophthalmopathy was classified as; a) "active" [signs present for $<6$ months, Clinical Activity Score (CAS) $\geq 3$ ] or "chronic" (signs present for $>12$ months, CAS $<3$ ]; and b) Nunery types 1 (mainly involving the orbital fat without restrictive myopathy) or 2 (with diplopia and restrictive myopathy) [12]. UER was identified as an important sign of thyroid eye disease that can occur in association with other features or as an isolated abnormality, especially in patients with Hashimoto thyroiditis. In patients with Graves hyperthyroidism UER had been present for at least 3 months after they had become euthyroid (with normal TSH). The degree of exophthalmos (mm) was measured using a Hertel exophthalmometer. Nepean and Geelong Hospitals Human Ethics Committees approved the retrospective study. Consent forms were not required.

\section{Thyroglobulin and thyroid peroxidase antibody measure- ments}

Serum TG and TPO antibodies were measured by Barratt \& Smith Pathology, Sydney, Australia, using commercial kits according to the manufacturers' instructions. A positive test was taken as a tire of $>20$, for both antibodies.

\section{Other tests}

Plasma free Thyroxin (fT4) and Thyrotropin (TSH) were measured by Barratt \& Smith Pathology, Sydney, Australia, using commercial kits according to the manufacturers' instructions.

\section{Statistical analysis}

Statistical analysis was carried out using SigmaStat (version 2.0; Jandel Co., San Rafael, CA, USA). Mean ( \pm SE) antibody titres for groups of patients were compared using the Mann-Whitney non-parametric test. Prevalences of positive antibody tests in the various groups were compared statistically using the $\mathrm{X}^{2}$ test or the Fishers exact test for five or less expected observations in one or more cells. In all tests, a p-value of $<0.05$ was taken as significant.

\section{Results}

We have analysed the relationship between TPO and TG antibodies and ophthalmopathy and chronic UER in patients with GD, Hashimoto thyroiditis and transient (sub acute, silent) thyroiditis (sub acute thyroiditis is not an autoimmune disease). TPO and TG antibody results were expressed as serum titre, a cut off value of $>20$ being taken as positive, for both antibodies. Patient demographics, any treatment, eye signs, smoking status and serum titres of TG and TPO antibodies for GD are summarised in table 1, for Hashimoto thyroiditis in table 2 and for patients with transient thyroiditis in table 3 . In this study we were particularly interested in the prevalence's of negative antibody tests in patients with thyroid autoimmunity and ophthalmopathy or isolated UER. The prevalence's of negative TPO and TG antibody tests

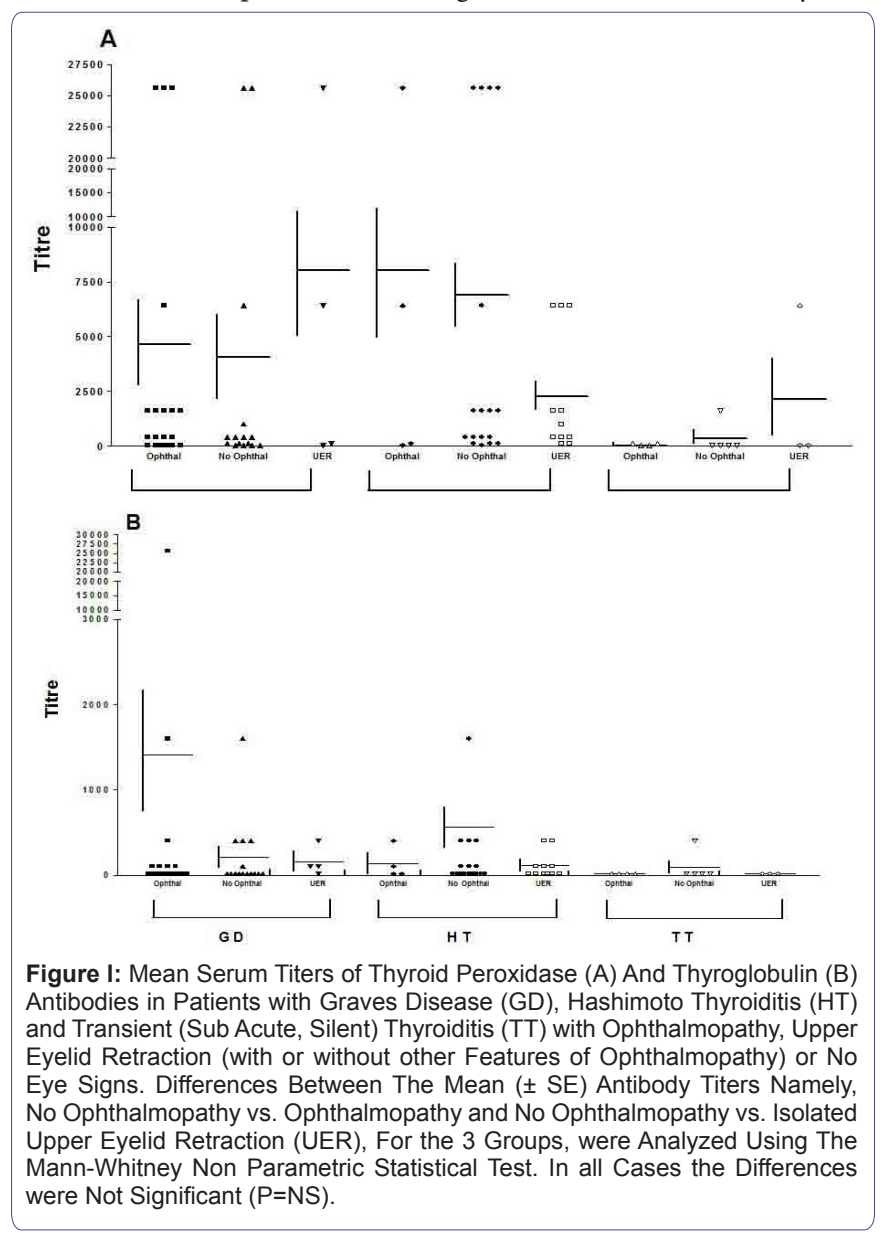


Citation: Wall JR, Lahooti H, El Kochairi I (2016) Thyroid Peroxidase and Thyroglobulin Antibodies and Ophthalmopathy in Patients with Graves' disease, Hashimoto Thyroiditis and Transient Thyroiditis. J Hum Endocrinol 1: 002.

- Page 3 of 7 •

\begin{tabular}{|c|c|c|c|c|c|c|c|c|c|c|c|}
\hline \multirow{2}{*}{ Patient No. } & \multirow{2}{*}{ Age } & \multirow{2}{*}{ Sex } & \multirow{2}{*}{ Treatment $^{1}$} & \multirow{2}{*}{ Smoker (Y/N) } & \multicolumn{4}{|c|}{ Ophthalmopathy } & \multirow{2}{*}{ No eye signs } & \multicolumn{2}{|c|}{ Thyroid Abs ${ }^{2}$} \\
\hline & & & & & Active $\left(\mathrm{CAS}^{3}>3\right)$ & Chronic (CAS <3) & Nunery $(1,2)$ & $\mathrm{UER}^{4}(\mathrm{Y} / \mathrm{N})$ & & TPO & TG \\
\hline 1 & 71 & $\mathrm{~F}$ & Nil & $\mathrm{N}$ & & & & $\mathrm{N}$ & $x$ & 400 & 400 \\
\hline 2 & 53 & $M$ & $\mathrm{Nil}$ & $Y$ & $x$ & & 2 & $Y$ & & 400 & $\mathrm{Neg}$ \\
\hline 3 & 58 & $\mathrm{~F}$ & Nil & $Y$ & & $x$ & 2 & $\mathrm{~N}$ & & 400 & Neg \\
\hline 4 & 45 & $\mathrm{~F}$ & $\mathrm{Nil}$ & $\mathrm{N}$ & & $x$ & 2 & $\mathrm{~N}$ & & 1600 & $\mathrm{Neg}$ \\
\hline 5 & 60 & $\mathrm{~F}$ & PTU & $\mathrm{Y}$ & $x$ & & & $Y$ & & 1600 & 400 \\
\hline 6 & 18 & $M$ & Nil & $\mathrm{N}$ & & & & $\mathrm{N}$ & $x$ & 6400 & 400 \\
\hline 7 & 22 & $M$ & $\mathrm{Nil}$ & $\mathrm{N}$ & & & & $\mathrm{N}$ & $x$ & 25600 & 1600 \\
\hline 8 & 36 & $\mathrm{~F}$ & Carb & $\mathrm{N}$ & & & & $\mathrm{N}$ & $x$ & $\mathrm{Neg}$ & $\mathrm{Neg}$ \\
\hline 9 & 62 & $\mathrm{~F}$ & Nil & $\mathrm{N}$ & & & & $Y$ & & 25600 & 100 \\
\hline 10 & 52 & $\mathrm{~F}$ & $\mathrm{Nil}$ & $\mathrm{N}$ & & & & $\mathrm{N}$ & $x$ & 400 & $\mathrm{Neg}$ \\
\hline 11 & 53 & $M$ & Nil & $\mathrm{N}$ & $x$ & & 1 & $\mathrm{Y}$ & & Neg & $\mathrm{Neg}$ \\
\hline 12 & 25 & $\mathrm{~F}$ & $\mathrm{Nil}$ & Not known & $x$ & & 1 & $Y$ & & 25600 & 25600 \\
\hline 13 & 58 & $\mathrm{~F}$ & Nil & $\mathrm{N}$ & & & $x$ & $Y$ & & $\mathrm{Neg}$ & $\mathrm{Neg}$ \\
\hline 14 & 43 & $\mathrm{~F}$ & Carb & $\mathrm{N}$ & & & & $\mathrm{N}$ & $x$ & $\mathrm{Neg}$ & Neg \\
\hline 15 & 29 & $\mathrm{~F}$ & nil & $Y$ & & & & $Y$ & & $\mathrm{Neg}$ & $\mathrm{Neg}$ \\
\hline 16 & 23 & $\mathrm{~F}$ & nil & $\mathrm{N}$ & & & & $Y$ & & 100 & 400 \\
\hline 17 & 40 & $\mathrm{~F}$ & nil & $Y$ & & & & $\mathrm{~N}$ & $x$ & 100 & neg \\
\hline 18 & 44 & $\mathrm{~F}$ & nil & $Y$ & $x$ & & 1 & $\mathrm{~N}$ & & 25600 & 100 \\
\hline 19 & 47 & $\mathrm{~F}$ & L-T4 & $\mathrm{N}$ & $x$ & & 1 & $Y$ & & 1600 & 100 \\
\hline 20 & 47 & $\mathrm{~F}$ & $\mathrm{Nil}$ & $\mathrm{N}$ & $x$ & & 2 & $Y$ & & 400 & 400 \\
\hline 21 & 39 & $\mathrm{~F}$ & L-T4 & $Y$ & $x$ & & 1 & $\mathrm{~N}$ & & $\mathrm{Neg}$ & $\mathrm{Neg}$ \\
\hline 22 & 41 & $\mathrm{~F}$ & Nil & $\mathrm{N}$ & & & & $\mathrm{N}$ & $x$ & 25600 & $\mathrm{Neg}$ \\
\hline 23 & 53 & $\mathrm{~F}$ & L-T4 & $Y$ & & $x$ & 2 & $\mathrm{~N}$ & & $\mathrm{Neg}$ & $\mathrm{Neg}$ \\
\hline 24 & 14 & $\mathrm{~F}$ & nil & $\mathrm{N}$ & & & & $\mathrm{N}$ & $x$ & 100 & $\mathrm{Neg}$ \\
\hline 25 & 36 & $M$ & Carb & $\mathrm{N}$ & $x$ & & 2 & $\mathrm{~N}$ & & 1600 & 100 \\
\hline 26 & 33 & $\mathrm{~F}$ & Carb & $\mathrm{N}$ & & & & $\mathrm{N}$ & $x$ & $\mathrm{Neg}$ & $\mathrm{Neg}$ \\
\hline 27 & 50 & $\mathrm{~F}$ & Nil & $\mathrm{N}$ & & & & $\mathrm{N}$ & $x$ & 400 & 100 \\
\hline 28 & 44 & $\mathrm{~F}$ & $\mathrm{Nil}$ & $\mathrm{N}$ & $x$ & & 1 & $\mathrm{~N}$ & & 400 & $\mathrm{Neg}$ \\
\hline 29 & 43 & $\mathrm{~F}$ & nil & $\mathrm{N}$ & $x$ & & 2 & $Y$ & & 6400 & \\
\hline 30 & 58 & $\mathrm{~F}$ & nil & $Y$ & $x$ & & 2 & $Y$ & & 6400 & 100 \\
\hline 31 & 64 & $\mathrm{~F}$ & $\mathrm{Nil}$ & $\mathrm{N}$ & & & & $Y$ & & 1600 & 100 \\
\hline 32 & 26 & $\mathrm{~F}$ & Nil & $\mathrm{N}$ & & & & $\mathrm{N}$ & $x$ & 25600 & 400 \\
\hline 33 & 53 & $\mathrm{~F}$ & $\mathrm{Nil}$ & $Y$ & $x$ & & 1 & $\mathrm{~N}$ & & 25600 & 1600 \\
\hline 34 & 76 & $\mathrm{~F}$ & L-T4 & $\mathrm{N}$ & & $x$ & 2 & $\mathrm{~N}$ & & $\mathrm{Neg}$ & $\mathrm{Neg}$ \\
\hline 35 & 69 & $\mathrm{~F}$ & Carb & $\mathrm{N}$ & & $x$ & 2 & $\mathrm{~N}$ & & $\mathrm{Neg}$ & $\mathrm{Neg}$ \\
\hline 36 & 44 & $\mathrm{~F}$ & Carb & $\mathrm{N}$ & $x$ & & 1 & $\mathrm{~N}$ & & 1600 & $\mathrm{Neg}$ \\
\hline 37 & 26 & $\mathrm{~F}$ & PTU & $\mathrm{N}$ & & & & $\mathrm{N}$ & $x$ & 400 & $\mathrm{Neg}$ \\
\hline 38 & 72 & $\mathrm{~F}$ & L-T4 & $\mathrm{N}$ & & & & $\mathrm{N}$ & $x$ & $\mathrm{Neg}$ & $\mathrm{Neg}$ \\
\hline 39 & 45 & $M$ & L-T4 & $Y$ & & & & $N$ & $x$ & 100 & $\mathrm{Neg}$ \\
\hline
\end{tabular}

Table 1: Demographics, Eye Signs and Serum Tires of Thyroid Peroxidase and Thyroglobulin Antibodies in Patients with Graves' disease.

${ }^{1}$ Carb $=$ Carbimazole, PTU = Propylthiouracil, L-T4 = L-thyroxin

${ }^{2} \mathrm{Abs}=$ Antibodies, expressed as titre; TPO $=$ Thyroid Peroxidase, $\mathrm{TG}=$ Thyroglobulin and a cut off value of $>20$ being taken as positive, for both antibodies, Neg $=$ Negative

${ }^{3} \mathrm{CAS}=$ Clinical Activity Score

${ }^{4} \mathrm{UER}=$ Upper eyelid retraction

in patients with and without active or chronic eye signs or UER are summarised in table 4 and mean ( \pm SE) antibody titres for patients with GD, Hashimoto thyroiditis and transient thyroiditis, with and without ophthalmopathy or UER, are shown in figure 1.
In patients with recent onset Graves hyperthyroidism, the prevalence's of negative TPO antibody tests in those with $(\mathrm{n}=14)$, and without $(\mathrm{n}=10)$, active ophthalmopathy were $21 \%$ and $30 \%$, respectively, which were not significantly different $\left(\mathrm{X}^{2}\right.$ test, $\left.\mathrm{p}=\mathrm{NS}\right)$ 
Citation: Wall JR, Lahooti H, El Kochairi I (2016) Thyroid Peroxidase and Thyroglobulin Antibodies and Ophthalmopathy in Patients with Graves' disease, Hashimoto Thyroiditis and Transient Thyroiditis. J Hum Endocrinol 1: 002.

- Page 4 of 7 •

\begin{tabular}{|c|c|c|c|c|c|c|c|c|c|c|c|}
\hline \multirow{2}{*}{ Patient no. } & \multirow{2}{*}{ Age } & \multirow{2}{*}{ Sex } & \multirow{2}{*}{ Treatment $^{1}$} & \multirow{2}{*}{ Smoker (Y/N) } & \multicolumn{4}{|c|}{ Ophthalmopathy } & \multirow{2}{*}{ No eye signs } & \multicolumn{2}{|c|}{ Thyroid Abs $^{2}$} \\
\hline & & & & & Active $\left(\mathrm{CAS}^{3}>3\right)$ & Chronic (CAS <3) & Nunery $(1,2)$ & $\mathrm{UER}^{4}(\mathrm{Y} / \mathrm{N})$ & & TPO & TG \\
\hline 1 & 50 & $\mathrm{~F}$ & Nil & Not known & & & & $\mathrm{N}$ & $x$ & 400 & Neg \\
\hline 2 & 53 & $\mathrm{~F}$ & L-T4 & Not known & & & & $\mathrm{N}$ & $x$ & 6400 & 1600 \\
\hline 3 & 10 & $\mathrm{~F}$ & Nil & $\mathrm{N}$ & & & & $\mathrm{N}$ & $x$ & 25600 & 400 \\
\hline 4 & 26 & $\mathrm{~F}$ & Nil & $\mathrm{N}$ & & & & $\mathrm{Y}$ & & 1000 & 100 \\
\hline 5 & 54 & $\mathrm{~F}$ & Nil & Not known & & & & $\mathrm{N}$ & $x$ & Neg & $\mathrm{Neg}$ \\
\hline 6 & 38 & $\mathrm{~F}$ & Nil & $\mathrm{N}$ & & & & $\mathrm{N}$ & $x$ & 200 & Neg \\
\hline 7 & 35 & $\mathrm{~F}$ & Nil & Not known & & & & $\mathrm{N}$ & $x$ & 400 & $\mathrm{Neg}$ \\
\hline 8 & 62 & $\mathrm{~F}$ & Nil; & $\mathrm{N}$ & & & & $\mathrm{Y}$ & & 1600 & 100 \\
\hline 9 & 66 & $\mathrm{~F}$ & Nil & Not known & & & & $\mathrm{N}$ & $x$ & 25600 & $\mathrm{Neg}$ \\
\hline 10 & 53 & $\mathrm{~F}$ & L-T4 & Not known & & & & $\mathrm{N}$ & $x$ & 1600 & 6400 \\
\hline 11 & 44 & $\mathrm{~F}$ & L-T4 & Not known & & & & $\mathrm{N}$ & $x$ & 1600 & $\mathrm{Neg}$ \\
\hline 12 & 75 & $\mathrm{~F}$ & Nil & $\mathrm{N}$ & & & & $\mathrm{N}$ & $x$ & 100 & 400 \\
\hline 13 & 62 & $\mathrm{~F}$ & L-T4 & $\mathrm{N}$ & $x$ & & 1 & $\mathrm{Y}$ & & 6400 & Neg \\
\hline 14 & 40 & $\mathrm{~F}$ & L-T4 & $\mathrm{N}$ & & & & $\mathrm{Y}$ & & 6400 & $\mathrm{Neg}$ \\
\hline 15 & 49 & $\mathrm{~F}$ & Nil & Not known & & & & $\mathrm{Y}$ & & 1600 & Neg \\
\hline 16 & 40 & $\mathrm{~F}$ & Nil & $\mathrm{N}$ & & & & $\mathrm{N}$ & $x$ & 25600 & 100 \\
\hline 17 & 65 & $\mathrm{~F}$ & Nil & Not known & & & & $\mathrm{N}$ & $x$ & 25600 & Neg \\
\hline 18 & 36 & $\mathrm{~F}$ & L-T4 & Not known & & & & $\mathrm{N}$ & $x$ & Neg & $\mathrm{Neg}$ \\
\hline 19 & 57 & $\mathrm{~F}$ & L-T4 & Not known & $x$ & & 2 & $\mathrm{~N}$ & & 100 & 100 \\
\hline 20 & 69 & $\mathrm{~F}$ & Nil & $\mathrm{Y}$ & & & & $\mathrm{Y}$ & & 400 & $\mathrm{Neg}$ \\
\hline 21 & 48 & $\mathrm{~F}$ & L-T4 & $\mathrm{N}$ & & & & $\mathrm{N}$ & $x$ & 400 & $\mathrm{Neg}$ \\
\hline 22 & 75 & $\mathrm{~F}$ & Nil & $\mathrm{N}$ & & & & $\mathrm{N}$ & $x$ & 400 & 100 \\
\hline 23 & 60 & $\mathrm{~F}$ & L-T4 & $\mathrm{N}$ & & & & $\mathrm{N}$ & $x$ & 1600 & $\mathrm{Neg}$ \\
\hline 24 & 39 & $\mathrm{~F}$ & L-T4 & $\mathrm{N}$ & & & & $\mathrm{N}$ & $x$ & 100 & 1600 \\
\hline 25 & 32 & $\mathrm{~F}$ & nil & $\mathrm{N}$ & & & & $\mathrm{Y}$ & & 100 & 100 \\
\hline 26 & 39 & $\mathrm{~F}$ & L-T4 & $\mathrm{N}$ & & & & $\mathrm{Y}$ & & 100 & Neg \\
\hline 27 & 57 & $\mathrm{~F}$ & L-T4 & $\mathrm{N}$ & & & & $\mathrm{Y}$ & & 400 & 400 \\
\hline 28 & 46 & $\mathrm{~F}$ & Nil & $\mathrm{N}$ & & & & $\mathrm{Y}$ & & 6400 & 400 \\
\hline 29 & 55 & $\mathrm{~F}$ & L-T4 & $\mathrm{N}$ & & & & Y & & 400 & Neg \\
\hline 30 & 53 & $\mathrm{~F}$ & L-T4 & Y & & & & Y & & 6400 & $\mathrm{Neg}$ \\
\hline 31 & 36 & $\mathrm{~F}$ & Nil & Not known & & & & $\mathrm{N}$ & $x$ & 1600 & 400 \\
\hline 32 & 48 & $\mathrm{~F}$ & Nil & $\mathrm{N}$ & $x$ & & 2 & $\mathrm{Y}$ & & Neg & $\mathrm{Neg}$ \\
\hline 33 & 69 & $\mathrm{~F}$ & L-T4 & $\mathrm{N}$ & $x$ & & 1 & $\mathrm{Y}$ & & 25600 & Neg \\
\hline
\end{tabular}

Table 2: Demographics, Eye Signs and Serum Tires of Thyroid Peroxidase and Thyroglobulin Antibodies in Patients with Hashimoto Thyroiditis.

${ }^{1}$ Carb $=$ Carbimazole, PTU = Propylthiouracil, L-T4 = L-thyroxin

${ }^{2} \mathrm{Abs}=$ Antibodies, expressed as titre; TPO $=$ Thyroid Peroxidase, TG $=$ Thyroglobulin and a cut off value of $>20$ being taken as positive, for both antibodies Neg $=$ Negative

${ }^{3} \mathrm{CAS}=$ Clinical Activity Score

${ }^{4} \mathrm{UE}=$ Upper eyelid retraction

(Table 4). In those with chronic disease, i.e., long standing hyperthyroidism ( $>2$ yr since diagnosis, CAS <3), with $(\mathrm{n}=6)$ and without $(\mathrm{n}=5)$ ophthalmopathy of $>12$ months duration, the prevalence's were $67 \%$ and $20 \%$, respectively, which were not significantly different (Fischer exact test, $\mathrm{p}=\mathrm{NS}$ ). TG antibodies were more often undetectable, or positive at a lower titre, than TPO antibodies, but the same trends were seen and there were no significant differences in prevalence's of negative tests between any of the 4 groups ( $\mathrm{X}^{2}$ tests, $\mathrm{p}=\mathrm{NS}$ ) (Table 4$)$. As seen in table 1 , the range of titres was similar in patients with Graves' disease with or without ophthalmopathy or UER, for both antibodies.
In patients with Hashimoto thyroiditis, in whom any eye signs were generally mild or manifest as isolated UER (Table 2), there were no significant differences between prevalence's of negative tests (Table 4) or range of titres (Table 2), for either antibody. While there was a tendency for high titres of TPO antibodies $(\geq 6400)$ to be protective for UER, but not ophthalmopathy (Table 2), this was not statistically significant $\left(\mathrm{X}^{2}\right.$ tests, $\left.\mathrm{p}=\mathrm{NS}\right)$. In patients with transient thyroiditis, there were again no significant differences in the range of titres (Table 3) or prevalence of negative antibody tests (Table 4) in patients with and without ophthalmopathy or isolated UER for either antibody $\mathrm{X}^{2}$ tests, $\mathrm{p}=\mathrm{NS}$ (Figure 1 ). 
Citation: Wall JR, Lahooti H, El Kochairi I (2016) Thyroid Peroxidase and Thyroglobulin Antibodies and Ophthalmopathy in Patients with Graves' disease, Hashimoto Thyroiditis and Transient Thyroiditis. J Hum Endocrinol 1: 002.

- Page 5 of $7 \cdot$

\begin{tabular}{|c|c|c|c|c|c|c|c|c|c|c|c|c|}
\hline \multirow{2}{*}{ Patient no. } & \multirow{2}{*}{ Age } & \multirow{2}{*}{ Sex } & \multirow{2}{*}{ Dx ${ }^{1}$} & \multirow{2}{*}{ Treatment } & \multirow{2}{*}{ Smoker } & \multicolumn{4}{|c|}{ Ophthalmopathy } & \multirow{2}{*}{ No eye signs } & \multicolumn{2}{|c|}{ Thyroid Abs $^{2}$} \\
\hline & & & & & & Active $\left(\mathrm{CAS}^{3}>3\right)$ & Chronic $(C A S<3)$ & Nunery $(1,2)$ & UER ${ }^{4}(\mathrm{Y} / \mathrm{N})$ & & TPO & TG \\
\hline 1 & 46 & $\mathrm{~F}$ & SAT & Nil & $Y$ & $x$ & & 1 & & & $\mathrm{Neg}$ & $\mathrm{Neg}$ \\
\hline 2 & 60 & M & SAT & $\mathrm{Nil}$ & Not known & & & & & $x$ & Neg & $\mathrm{Neg}$ \\
\hline 3 & 41 & $\mathrm{~F}$ & SAT & Nil & $\mathrm{N}$ & & & & $\mathrm{Y}$ & & $\mathrm{Neg}$ & $\mathrm{Neg}$ \\
\hline 4 & 43 & $\mathrm{~F}$ & SAT & Nil & Not known & & & & & $x$ & Neg & $\mathrm{Neg}$ \\
\hline 5 & 52 & $\mathrm{~F}$ & SAT & Nil & $\mathrm{N}$ & $x$ & & 2 & & & Neg & $\mathrm{Neg}$ \\
\hline 6 & 26 & $\mathrm{~F}$ & ST & Nil & Not known & & & & $\mathrm{Y}$ & & Neg & $\mathrm{Neg}$ \\
\hline 7 & 47 & $\mathrm{~F}$ & ST & Nil & Not known & & & & & $x$ & 1600 & 400 \\
\hline 8 & 24 & $\mathrm{~F}$ & ST & Nil & $\mathrm{N}$ & & & & & $x$ & $\mathrm{Neg}$ & $\mathrm{Neg}$ \\
\hline 9 & 24 & $\mathrm{~F}$ & ST & Nil & $\mathrm{N}$ & & & & & $x$ & $\mathrm{Neg}$ & $\mathrm{Neg}$ \\
\hline 10 & 57 & $\mathrm{~F}$ & ST & Nil & Not known & $x$ & & 1 & $\mathrm{Y}$ & & 100 & Neg \\
\hline 11 & 68 & $\mathrm{~F}$ & ST & Nil & Not known & $x$ & & 1 & & & 100 & $\mathrm{Neg}$ \\
\hline 12 & 53 & $\mathrm{~F}$ & ST & Nil & $\mathrm{Y}$ & & & & $\mathrm{Y}$ & & 6400 & $\mathrm{Neg}$ \\
\hline
\end{tabular}

Table 3: Demographics, Eye Signs and Serum Tires of Thyroid Peroxidase and Thyroglobulin Antibodies in Patients with Transient Thyroiditis.

${ }^{1}$ SAT = Subacute Thyroiditis, ST = Silent Thyroiditis

${ }^{2} \mathrm{Abs}=$ Antibodies, expressed as titre; TPO $=$ Thyroid Peroxidase, $\mathrm{TG}=$ Thyroglobulin and a cut off value of $>20$ being taken as positive, for both antibodies, Neg $=$ Negative

${ }^{3} \mathrm{CAS}=$ Clinical Activity Score

${ }^{4} \mathrm{UER}=$ Upper Eyelid Retraction

\begin{tabular}{|c|c|c|c|c|}
\hline \multirow[t]{2}{*}{ Group ${ }^{1}$} & \multirow[t]{2}{*}{ Number } & \multicolumn{2}{|c|}{$\begin{array}{c}\text { Negative antibody } \\
\text { test }^{2}\end{array}$} & \multirow[t]{2}{*}{ P value ${ }^{3}$} \\
\hline & & TPO & TG & \\
\hline $\begin{array}{c}\text { Recent GH }(<2 \text { yr since Dx }) \\
\text { with no eye signs }\end{array}$ & 10 & $3(30 \%)$ & $6(60 \%)$ & \\
\hline $\begin{array}{l}\text { Recent GH ( }<2 \text { yr since Dx) } \\
\text { with active ophthalmopathy }\end{array}$ & 14 & $3(21 \%)$ & $6(43 \%)$ & $0.67,0.68$ \\
\hline $\begin{array}{c}\mathrm{GH}>2 \text { yr duration and no eye } \\
\text { signs }\end{array}$ & 5 & $1(20 \%)$ & $4(80 \%)$ & \\
\hline $\begin{array}{c}\mathrm{GH}>2 \text { yr duration and ophthal- } \\
\text { mopathy }>1 \text { yr duration }\end{array}$ & 6 & $4(67 \%)$ & $6(100 \%)$ & $0.30,0.23$ \\
\hline $\begin{array}{c}\text { GH + UER (with or without } \\
\text { other eye signs) }\end{array}$ & 16 & $6(38 \%)$ & $7(44 \%)$ & $0.70,0.36$ \\
\hline HT and no eye signs & 18 & $2(11 \%)$ & $10(56 \%)$ & \\
\hline HT + active ophthalmopathy & 4 & $1(25 \%)$ & $2(50 \%)$ & $0.47,1.0$ \\
\hline $\begin{array}{l}\text { HT + UER (with or without } \\
\text { other eye signs) }\end{array}$ & 14 & $1(7 \%)$ & $8(57 \%)$ & $1.0,0.79$ \\
\hline TT and no eye signs & 5 & $4(80 \%)$ & $4(80 \%)$ & \\
\hline $\begin{array}{c}\text { TT + active ophthalmopathy } \\
\text { with or without UER }\end{array}$ & 7 & $4(57 \%)$ & $4(57 \%)$ & $0.52,1.0$ \\
\hline
\end{tabular}

Table 4: Prevalences of Negative Thyroid Antibody Tests in Patients with Graves' disease, Hashimoto Thyroiditis and Transient (Sub Acute, Silent) Thyroiditis with and without Eye Signs.

${ }^{1} \mathrm{GH}=$ Graves Hyperthyroidism, HT = Hashimoto Thyroiditis, TT = Transient (sub acute, silent) Thyroiditis, UER = Upper Eyelid Retraction, Dx = Diagnosis

${ }^{2} \mathrm{TPO}=$ Thyroid Peroxidase $\mathrm{TG}=$ Thyroglobulin

${ }^{3}$ Statistical analyses refer to $\mathrm{X}^{2}$ tests comparing patients with ophthalmopathy vs the corresponding group with no eye signs

Considering all patients with chronic UER (with or without other signs of ophthalmopathy) associated with Graves hyperthyroidism, Hashimoto thyroiditis or transient thyroiditis there were no significant relationships between this eye sign and either negative antibody tests or range of titres (Tables 1-3) for either antibody. As shown in figure 1, mean $( \pm$ SE) for the various groups of patients with

and without ophthalmopathy or UER were not significantly different from each other (Mann-Whitney test, all $\mathrm{p}=\mathrm{NS}$ ) (Figure 1).

Finally, more patients with Graves disease and ophthalmopathy were smokers (39 \% vs. $8 \%$ of patients without eye signs), which was slightly greater (42\%) when only ophthalmopathy was considered and slightly less (27\%) when UER was considered (25\%). All 5 patients with GD, Hashimoto thyroiditis or silent thyroiditis who smoked and had negative TPO antibody tests had eye signs namely, chronic UER in one, congestive ophthalmopathy (Nunery type 1) in two and congestive ophthalmopathy and eye muscle dysfunction (Nunery type 2) in two patients.

\section{Discussion}

The main thyroid antibodies are those targeting TPO in the follicular cell membrane, TG in the colloid and the TSHR in the thyroid follicular cell membranes. The latter is associated with hyperthyroidism and serum antibodies against TPO and TG are markers for the thyroid autoimmune process of Hashimoto thyroiditis and GD. Low titres of thyroid antibodies are sometimes found in patients with sub acute thyroiditis and, more often, in those with silent thyroiditis in whom titres tend to increase with time. TPO antibodies have been shown to be cytotoxic to thyroid cells in vitro [26] thus likely to play a role in the development of hypothyroidism in patients with Hashimoto thyroiditis. While TG antibodies are less often positive, or positive but in low titres, than TPO antibodies, in all 3 disorders, they are also markers of the thyroid autoimmune process, but probably not directly pathogenetic. Khoo et al., [22,23] reported that TPO antibodies were negatively related to ophthalmopathy namely, that low titres, or undetectable antibodies, were risk factors for the development of ophthalmopathy, particularly in patients with TSHR antibodies who smoked. These workers postulated that TPO antibodies were somehow protected against ophthalmopathy. Our findings, reported here, do not support such a hypothesis as we find no close relationship between either antibody and active ophthalmopathy or UER in patients with GD, Hashimoto 
Citation: Wall JR, Lahooti H, El Kochairi I (2016) Thyroid Peroxidase and Thyroglobulin Antibodies and Ophthalmopathy in Patients with Graves' disease, Hashimoto Thyroiditis and Transient Thyroiditis. J Hum Endocrinol 1: 002.

thyroiditis or transient thyroiditis. We found that antibody titres were similar for patients with GD with and without active eye signs (ophthalmopathy and/or UER), for both antibodies. Although we previously reported that a TPO antibody titre of $>400$ was protective of UER but not ophthalmopathy in patients with Hashimoto thyroiditis but not Graves disease [21], this was not reproduced here, possibly because of the small numbers of patients studied.

Our findings generally support those of Ekstein et al., [24] and Wright-Pascoe et al., [25] who found no close relationship between TPO and TG antibodies and ophthalmopathy. Indeed, the latter group found a positive relationship between both TPO and TG antibodies and ophthalmopathy in patients with GD. Although $67 \%$ of a small group of patients with chronic GO in our study had negative anti-TPO antibodies compared to $20 \%$ of those with long-standing hyperthyroidism without eye signs ( $100 \%$ vs. $44 \%$ for TG antibodies), this was not significant possibly because of the small group sizes and wide range of titres.

The finding that all 5 patients with GD, Hashimoto thyroiditis or transient thyroiditis and negative TPO antibody tests who smoked had eye signs suggests that this combination does indicate high risk for eye signs in this group of patients. Smoking is a definite risk factor for ophthalmopathy $[27,28]$, and we report here for the first time a modest relationship between smoking and chronic UER as a dominant feature of ophthalmopathy. It is likely that the association reported by Khoo et al., [22,23] reflects this, rather than a role of TPO antibodies per se. In conclusion, our study did not confirm a significant relationship between ophthalmopathy and thyroid antibodies in patients with GD, Hashimoto thyroiditis or transient (sub acute, silent, post partum) thyroiditis. Future studies should focus on the nature and significance of specific autoimmunity against eye muscle and orbital fibroblast antigens in patients with ophthalmopathy - including those with so-called euthyroid Graves' disease - and the related chronic upper eyelid disorder that is so common in patients with Hashimoto thyroiditis.

\section{Acknowledgement}

This research was supported by a Cy-Pres Award, Toronto, Canada and by a grant from NBMLHD. We thank Ms. Delene Assam for help with the development of the database used in this study.

\section{References}

1. Bartley GB, Gorman CA (1995) Diagnostic criteria for Graves' ophthalmopathy. Am J Ophthalmol 119: 792-795

2. El-Kaissi S, Frauman AG, Wall JR (2004) Thyroid-associated ophthalmopathy: a practical guide to classification, natural history and management. Intern Med J 34: 482-491.

3. Burch HB, Wartofsky L (1993) Graves' ophthalmopathy: current concepts regarding pathogenesis and management. Endocr Rev 14: 747-793.

4. Tjiang $\mathrm{H}$, Lahooti $\mathrm{H}$, McCorquodale $\mathrm{T}$, Parmar KR, Wall JR (2010) Eye and eyelid abnormalities are common in patients with Hashimoto's thyroiditis. Thyroid 20: 287-290.

5. Gopinath B, Ma G, Wall JR (2007) Eye signs and serum eye muscle and collagen XIII antibodies in patients with transient and progressive thyroiditis. Thyroid 17: 1123-1129.

6. Weetman AP (1997) Eyeing up Graves' ophthalmopathy. Mol Cell Endocrinol 126: $113-116$
7. Paschke R, Vassart G, Ludgate M (1995) Current evidence for and against the TSH receptor being the common antigen in Graves' disease and thyroid associated ophthalmopathy. Clin Endocrinol (Oxf) 42: 565-569.

8. Bahn RS (2003) Clinical review 157: Pathophysiology of Graves' ophthalmopathy: the cycle of disease. J Clin Endocrinol Metab 88: 1939-1946.

9. Kloprogge S, Kowal L, Wall J, Frauman AG (2005) The clinicopathologic basis of Graves' ophthalmopathy: a review. Eur J Ophthalmol 15: 315-323.

10. Solovyeva TP (1989) Endocrine ophthalmopathies: Problems of rational classification. Orbit 8: 193-198.

11. Kasper M, Archibald C, De Bellis AM, et al. (2002) Eye muscle antibodies and subtype of thyroid-associated ophthalmopathy. Proc Intel Sym. on Thyroid Associated Ophthalmopathy, Kyoto, Japan, October 2000, thyroid 12: 187-191.

12. Nunery WR, Martin RT, Heinz GW, Gavin TJ (1993) The association of cigarette smoking with clinical subtypes of ophthalmic Graves' disease. Ophthal Plast Reconstr Surg 9: 77-82.

13. Gopinath B, Adams CL, Musselman R, Tani J, Wall JR (2007) Antibodies against calsequestrin and type XIII collagen are good markers for chronic upper eyelid retraction. Ocul Immunol Inflamm 15: 81-88.

14. Yamada M, Li AW, Wall JR (2000) Thyroid-associated ophthalmopathy: clinical features, pathogenesis, and management. Crit Rev Clin Lab Sci 37: 523549

15. Wall JR, Salvi M, Bernard NF, Boucher A, Haegert D (1991) Thyroid-associated ophthalmopathy--a model for the association of organ-specific autoimmune disorders. Immunol Today 12: 150-153.

16. Bell A, Gagnon A, Grunder L, Parikh SJ, Smith TJ, et al. (2000) Functional TSH receptor in human abdominal preadipocytes and orbital fibroblasts. Am J Physiol Cell Physiol 279: 335-340.

17. Kubota S, Gunji K, Ackrell BA, Cochran B, Stolarski C, et al. (1998) The 64-kilodalton eye muscle protein is the flavoprotein subunit of mitochondrial succinate dehydrogenase: the corresponding serum antibodies are good markers of an immune-mediated damage to the eye muscle in patients with Graves' hyperthyroidism. J Clin Endocrinol Metab 83: 443-447.

18. Hägg P, Rehn M, Huhtala $P$, Väisänen T, Tamminen M, et al. (1998) Type XIII collagen is identified as a plasma membrane protein. J Biol Chem 273: $15590-15597$.

19. Kahaly G, Förster G, Hansen C (1998) Glycosaminoglycans in thyroid eye disease. Thyroid 8: 429-432.

20. Hansen C, Otto E, Kuhlemann K, Förster G, Kahaly G (1996) Glycosaminoglycans in autoimmunity. Clin Exp Rheumatol 14: 59-67.

21. El Kochairi I, Champion B, Wall JR (2014) Risk Factors for the Development of Ophthalmopathy in Patients with Hashimoto's Thyroiditis. Ophthalmology Research: An international journal 2: 177-188.

22. Khoo DH, Ho SC, Seah LL, Fong KS, Tai ES, et al. (1999) The combination of absent thyroid peroxidase antibodies and high thyroid-stimulating immunoglobulin levels in Graves' disease identifies a group at markedly increased risk of ophthalmopathy. Thyroid 9: 1175-1180.

23. Goh SY, Ho SC, Seah LL, Fong KS, Khoo DHC (2004) Thyroid autoantibody profiles in ophthalmic dominant and thyroid dominant Graves' disease differ and suggest ophthalmopathy is a multiantigenic disease Clinical Endocrinology 60: 600-607.

24. Eckstein AK, Plicht M, Lax H, Hirche H, Quadbeck B, et al. (2004) Clinical results of anti-inflammatory therapy in Graves' ophthalmopathy and association with thyroidal autoantibodies. Clin Endocrinol (Oxf) 61: 612-618.

25. Wright-Pascoe R, Smikle MF, Barton EN, James OB (1999) Clinical results of anti-inflammatory therapy in Graves' ophthalmopathy and association with thyroidal autoantibodies. Hum Antibodies 9: 161-164.

26. Bogner U, Wall JR, Schleusener H (1987) Cellular and antibody mediated cytotoxicity in autoimmune thyroid disease. Acta Endocrinol Suppl (Copenh) 281: 133-138. 
Citation: Wall JR, Lahooti H, El Kochairi I (2016) Thyroid Peroxidase and Thyroglobulin Antibodies and Ophthalmopathy in Patients with Graves' disease, Hashimoto Thyroiditis and Transient Thyroiditis. J Hum Endocrinol 1: 002.

- Page 7 of 7 •

27. Krassas GE, Wiersinga W (2006) Smoking and autoimmune thyroid disease: the plot thickens. Eur J Endocrinol 154: 777-780.
28. Pontikides N, Krassas GE (2002) Influence of cigarette smoking on thyroid function, goiter formation and autoimmune thyroid disorders. Hormones (Athens) 1: 91-98. 